\title{
How MBA programs help the wine producers to innovate creating new employments?
}

\author{
Delphine Veissiere \\ WTBA, via dei Tigli 35, 20020 Arese, Italy
}

\begin{abstract}
People love innovation: they are fascinating and usually curious to know how it works. But people love it until it affects them. The biggest obstacle is not technology but it is we humans and the institutions we live in. Both are stubbornly resistant to experimentation and to the change of the routine and the relative corporate organization. During the last fifteen years, a large room has been opened to the technological innovation in the vineyard and in the cellar but the new way to reach the final customer and to keep it loyal have been missed. The customer experience topic and the different gap of the customer satisfaction a producer should monitor and shorten, are rarely developed in the marketing training sessions in the MBA programs. It exists a real gap between the consumer perception and the way in which the wine is promoted. Producers are not aware about the new marketing techniques that should help them to grow and create new jobs on top of the wine production activities.
\end{abstract}

\section{Introduction}

Over the past decades the global wine production has undergone fundamental changes, characterized by the emergence of New World producers and the changing of the consumer behaviors. The new shape of competition has pushed towards the application of strict rules and techniques for wine standardization, processes optimization, certifications and cost reduction in order to increase the international competitiveness. At the same time, the concern about the environmental impact of wine production and about the public health - especially in France - has increased because of changes in consumers' awareness and in producers' innovative projects supported by government incentives. On the other hand, credit crunch in 2007, currency depreciations (of Sterling for example), rising fuel costs and other operative costs in wine production and distribution have generated a change in the consumer behaviors and most of them (like in the US) have switched purchases to non-premium wines while in Europe, the global financial crisis has obliged wine producers to offer substantial discounts on prices so as to offer quality wine products at an attractive price, as it happens for the New World wines (US, Argentina, Chile, Australia and South Africa).

As a result, big players have been obliged to leave non-core businesses and run business unit disposals, reinforcing their attention exclusively on premium brands while many small wine business owners are questioning about the usefulness of innovating. In many cases, the small growers have been growing grapes and making wine for years and passed down for generations in the family. Fortunately, many young producers are aware that innovation creates value and new employments and different wine MBA programs are ready to support them. But the lack of cross-border programs able to help the producers to become innovators is a consistent obstacle to the changes requested by the global wine market. Globalization and technology have disruptive influences on the traditional ways of producing, marketing and selling wines. As noted by the participants of the first Global Conference on wine business education, the wine industry urgently needs to improve the business and management skills of its professionals. While a passion for wine is a pre-requisite and technical wine knowledge is an advantage, a good understanding of finance, sales and marketing are required [1].

Across the globe, the foundation, focus and maturation of wine business education is a varied lot. The wine business education at universities around the world is often found in a school focused on the sciences, viticulture and wine production, while it could be embedded within a business school. Countries such as Argentina, Canada, Chile, China, Germany, New Zealand and Spain have not established specific degree programs for wine business. They have agricultural schools and degree programs centered on production and programs that more broadly address agricultural business [2].

In that context our work has been to investigate the gaps between the final customer needs and the winery business strategy and to analyse the role of innovation and higher education programs.

To achieve this target, we considered two main elements:

1) key facts showing the world wine industry changes and the trend in higher wine education;

2) the presence of innovation in the existing wine business strategy (WBS).

Finally, we have analyzed the adequacy of the wine business education programs available in the world and the new competencies required by the world wine market. 


\section{Key facts}

While the major wine producing countries have lost their international competitiveness since the early 2000s and the wine companies are struggling to maintain their strategic positions, the success of the New world wines around the world has created an explosive demand in international wine education programs (WSET, Institute of Master of wine) especially in Asia (especially China, Hong Kong) and in international MBAs programs specialized in wine business. The growing unemployment rates registered in various old world countries and the family wine businesses transmission to new owners - especially in Italy and France - are opening a new issue. Institutions and employers are questioning about the ways of creating new jobs internalizing the new competencies and skills required by the wine industry changes. Different forms of innovation are required and it seems that the adoption of the IT technologies - along with globalization - should play a role of accelerator. As highlighted by Shift Happens from the Sonoma State University, the new challenge is "to prepare students for jobs that don't yet exist, using technologies that haven't yet been invented, in order to solve problems we don't even know are problems yet".

\subsection{World wine industry innovations}

Since the reform of the EU wine market adopted by the Council of Ministers in April 2008, different initiatives have been launched to reinforce the competitiveness of the EU wine sector and to favor solutions to better structure the sector. A funding budget for each country has been provided allowing to the wine company to be helped in their promotion plan outside the EU, innovation, restructuring and modernization of the production chain, support for green harvesting, crisis management. In the other hand, some New world countries such as Australia help the wine growers to produce the wines consumers want. In either parts of the world great efforts have been done to develop the hospitality and wine tourism businesses.

Most of the innovation programs concern generally the implementation of new industrial production process and the quality enhancement of the wine while the digital marketing tools are developed by other technology-driven sectors. The relative knowledge is then hardly transferred to the wine company group (called the "proactives") that are ready to invest to run a digital transformation of their organization and business model.

To have a clearer vision of the overall innovations that occur in the global wine market and then design the adequacy between them and the existing wine business strategies followed in the industry, we have gathered data on the online media websites (i.e. newspaper, television and radio websites) and individual wine company websites to understand where they are located in the wine industry value chain. The key words used to search for information in these websites included wine, innovation, marketing, IT technologies, price, promotion, hospitality and distribution. The collected data were filtered so that only relevant innovations were included; innovations that were excluded were those that were implemented more than ten years ago.

\section{Aromatic wines and low-alcohol content wines}

Product innovation is an important way for companies to differentiate their products from competing products. Product innovation can occur through the development of completely new products, changes to the features of existing products, changes to product packaging or changes to additional services provided by the company. For example, several New Zealand wineries are now producing low alcohol wines that are obtained thanks to innovative research and development in the vineyard where it is possible to slow the rate of sugar production without slowing flavor development.

A recent report published by Wine Intelligence found that across eight markets selected for study (the United States, Canada, UK, France, Germany, Denmark, Sweden, Switzerland) buyers of sub-10.5 per cent alcohol-by-volume wines now account for 38 per cent of consumers; that is more than 80 million regular wine drinkers.

\section{Eco-innovation}

Eco-innovation in the wine industry includes a wide set of actions and possible investments, which might mitigate the environmental impact of wine production and recent trends show that firms are increasingly committed. Into the European Eco-Prowine project, the wineries can adhere for examples to private standards or participate in certification programs so as to guarantee to their final customers the sustainability of their production process. Ecoinnovation could bring relevant savings of material costs and for SMEs the potential to improve material productivity is estimated to be even higher than for large enterprises [3]. It is then a driver of the wine company competitive advantage [4].

\section{Wine software applications}

The exponential growth in the digital media space in recent years, attract more customers and high-net-worth individuals who are embracing technology as a source of information. An article published in 2011 by the Western Farm Press noted that more than 450 wine-related applications are now available on the iPhone and other mobile devices while more than 14 million online conversations about wine, providing recommendations, reviewing vintages and suggesting the best wineries to visit have been registered on Facebook, Twitter and other social media. The digital technologies allow brands and wine companies to add a layer to the client experience creating value and a long-term relationship.

\section{$Q R$ codes and e-tracking}

Quick Response (QR) codes are another recent technological development. A QR code is a two-dimensional barcode that smartphones can read. They can be used to direct the consumer in a store through to product or brand information on a company website. Asian consumers are particularly prevalent in their use of QR codes and it appears that New Zealand wineries - for example exporting to Asian markets - are the most likely companies to include this technology on their labels. 


\section{CRM and business support systems}

CRM mostly concerns the small/medium-sized wineries (SMEs) that are generally using spreadsheets or low-level financial planning tools. It means that most of them are not able to track every critical activity that occurs in the winery business cycle. Today, new high-tech companies are offering to the SME's in the wine industry the opportunity to afford and leverage the same robust global business management and financial reporting capabilities that have long been in use only by larger wineries.

\section{Collaboration and collective actions}

The cluster modelling approach has been widely used in studying wine industries to examine collective action in the wine industry specific to a defined location such France or Australia for example. French wine companies are competing both in the domestic and international markets but they are following collaboration initiatives set up by regional organizations such as l'Union des Grands Crus de Bordeaux (UGCB) to promote their wines abroad. In the other hand, collective action in the value chain have been done by the Australian producers in adjusting their business models through the development of more contracting, leasing, share farming and cooperative arrangements to reach better financial performance.

Actually, for Porter [5] clusters have four salient features:

- boundaries that are not determined by geographic or political considerations but by the linkages and complementarities across industries and institutions that are most important to competition;

- clusters that rarely conform to standard industrial;

- classification systems, which fail to capture many important actors and relationships in competition;

- clusters promote both competition and cooperation;

- positive externalities are generated, including improved coordinative capacity and trust.

\section{Integration of the distribution network}

Many producers from the old world are setting their own distribution and import networks especially in the United States while some large estates have been acquired national networks of wine shops such as the Group Castel in France. With the purchase of Nicolas in 1988, Castel that is ranked the third world group for wine production and distribution in terms of volume and sales - became the owner of the largest chain of specialist wine shops in France. Through more than 500 stores located in the heart of major cities in France and abroad (Belgium, UK, Morocco and Russia), Nicolas offers over 1200 wines, champagnes and spirits.

\section{Direct-to-consumer business}

Born around ten years ago in the US three-tier market, the DTC business concerns wines shipped directly from wineries to consumers around the world, taking advantage of the new IT technologies. In the United States, The total value of the winery DTC shipping channel increased a whopping $15.5 \%$ over 2013 and reached $\$ 1.82$ billion in sales. Total volume of wine shipped increased $13.6 \%$ to 3.95 million cases. Psychology of satisfaction is there a key driver. In that context, the winery has to become through the community manager or the producer himself, a provider of stories - that should strengthen the direct relationships with the final customers who can eventually choose to believe them [6,7].

\section{Best practices transfers from the Luxury industry}

The luxury conglomerates like LVMH have changed their WBS integrating the new IT technologies to take on specialized functions such as public relations, communications, customer service, digital, CRM, marketing and e-commerce, among others on a global scale. The game rules that allow the wine company to engage the final customer are becoming the main goal of a formal wine business strategy. A competitive advantage should create revenues monitoring the following digital inputs such as monitoring the internet traffic growth and the actionable customer feedback and exceeded expectations.

As a result it appears that innovation is mainly support by the implementation of new technologies and the development of new marketing initiatives. Wine divisions belonging to global leading companies like LVMH have already undergone thorough digital transformations to probably unlock revenue gains while the large wine estates are concentrating their efforts on a cost-discipline strategy where the distribution networks around the world have to be rationalized. It is actually hard to find out where the SMEs are positioned in the Digital area. There is little evidence about their status of technology buyer vs. the one of innovator. Californian small wineries seems the leader in the way to digital transformation. The challenge of higher wine education is then to provide the relative knowledge that should be learned by the decision-maker to help the wine company/division to innovate and to choose the right way to do it - through the internalization or externalization of innovation.

\subsection{Trends in higher wine education}

The origins of a specialization in the wine business began in South Australia in 1977 at Roseworthy Agricultural College, today a part of the University of Adelaide's School of Agriculture, Food and Wine. The University's programs today have a "whole-of-wine-chain" focus, meaning that the viticulture and enology students are mandated to study also wine business and the wine business students must also study viticulture and enology. Moreover, it exists two kinds of Masters level qualifications focused on the wine business: the wine business MBAs and Master of science in wine management (for example OIV MSc). Both are granted to students who have demonstrated a high-level of knowledge in their field of study.

Although both awards are postgraduate courses, there are differences between them in terms of eligibility, focus and personal development. MBA is an executive-level business course usually designed for students with a first executive or management level experience while the Master of Science is designed for candidates who are at the beginning of their career, or for graduates who want a 
higher level qualification before entering the job market. Recently, the higher wine education panorama includes also Executive MBA programs which primarily designed to educate working executives, managers, entrepreneurs, and other business leaders. They concern students who are usually in the mid-stage of their career.

The proceedings of the first Global Conference on Wine Business Education (WBE) hosted by the Wine Business Institute at Sonoma State University in 2012 describe the different MBA programs that have been created since 1977:

- The MBA Wine Business Management at the Royal Agricultural College in England has been in operation for ten years and is the only Wine MBA offered in the United Kingdom. Actually, The UK is a net importer and is known as a hub of commerce in the international wine trade, thus the tenor of the program is pitched to the broader value chain rather than the management of wineries and vineyards.

- The Wine MBA at the Bordeaux School of Management is known for its worldwide perspective not only in France, but also in Adelaide, Hong Kong and Sonoma County.

- The University of Florence offers a Master Course in Wine Management and Marketing and a PhD in Wine Economics and Rural Development.

- The University of Cape Town offers a Wine Business Management Program run by the Graduate School of Business. The program consists of four modules run over a two year period. Each module consists of one week of full-time study at the university followed by 4 months of part-time work in which action learning projects are done in the students' work places.

- Sonoma State University in California offers three programs in wine business for students: an undergraduate degree in business with a concentration in wine business strategies, an executive Wine MBA and a Wine MBA with classes held during the evening.

New wine business MBA programs have been also created in different French business schools such as the INSEEC MBA in Bordeaux while institutions like the Kedge Business School offer a certificate in wine management destinated to future mid-management professionals. The School of Wine and Spirits Business of the ESC group in Dijon proposes a MSc in Wine management that is meant for students who have no experience in the wine industry. To complete this panorama it exists also some generic Executive MBA that offer elective modules dedicated to the wine business management like in the MIB school of Trieste in Italy.

MBAs programs usually help student to acquire general competencies and skills that come from the softer skills of communication and networking to the more quantitative skills of finance and demand forecasting, to help them to take decisions. In the wine industry, there is also a need for competence in negotiation, sales, comprehension of growing and winemaking, the full value chain and the global wine market. The technical competencies needed in the management of the vineyard and in wine-making are excluded.

As mentioned by the experts at the WBE conference in Sonoma, the competencies required in larger organizations vary by level in the organization. At the entry level, general wine knowledge, communication skills, presentation skills and an understanding of consumer behavior are required. At mid-level positions like Brand Manager and Regional Sales Manager, planning, problem-solving, quantitative and leadership skills come more to bear. At the VP and executive level, the competencies required broaden to include strategy, diplomacy and innovation. Small companies usually echo the needs of their larger cousins yet require the personnel at every level to wear many hats, to have a broader menu of competencies despite the title that may associate with the job. One competency that while not unique to small wineries, becomes quite crucial to the sustainability of the company, is thoughtful succession planning.

In the particular arena of hospitality and tourism, where many in the broader value chain are employed, ten specific competencies were enumerated: knowledge of the regulatory environment, sales and promotion management - etiquette, customer product lifecycles - CRM (experience marketing), consumer culture theory - qualitative, skills in collaboration, negotiation, relationships - competitors and complementary entities, knowledge of culture, history, architecture and language, event planning and talent management, knowledge of diverse yet related industries - hotels, restaurants, sensitivity to sustainability - ecotourism and agritourism, the ability to make decisions in a fast paced environment.

It appears then that the existing MBAs mainly focus their program on the product selling and wine branding delivering marketing, financial and supply chain competencies. Selling the experience given by wine is mainly reserved to the hospitality and wine tourism programs dedicated to the understanding of retail business. MBA programs are strongly oriented on the international management and they provide competencies that regards both leadership and project management skills. In parallel, it exists different MBA programs around the world that are not specialized in the wine business but in the management of the innovation that are now entering in the wine industry - i.e. MBAs specialized in digital marketing and luxury for example.

\section{Innovation in the existing wine business strategies (WBS)}

Since the 2000s, the wine business field has become a growing research topic for academics and professionals specialised in econometrics, business management, finance and marketing. In the new world, associations of wine economists (such as the American Association of Wine Economists) have been created along with international wine business symposium (see the Annual global conferences on wine business education). As a consequence, most of the wine business strategy articles and reports are provided directly by or in collaboration with the US and Australian university research departments. Various strategy experts have identified different ways of describing generic business strategies yet that is not simple to apply to the wine industry.

Classic business strategy can be applied to any industry, but in the case of the wine industry they are different 
considerations and differences that need to be taken into account in the setting and development of a business strategy. There are very few industries like the wine industry that incorporate both agriculture and manufacturing processes along with "homemade" marketing and distribution politics that bring thousands of competing and confusing labels to the final customers. The only other industry that comes close to producing so many labels is the music industry [8] in which the implementation of the IT technologies have revolutionize the traditional business model. By chance, wine cannot be digitalized and downloaded.

\subsection{Wine business strategy}

As a general statement, wine strategy could be defined as "a game plan for success" in which the key factors determine how to compete and to create value in the marketplace. In the large wine companies this game plan is developed and divided into premium and fine wine business units, or beer, wine and spirits divisions. It must be linked to corporate strategy in which the mission, vision, values and goals are explained whereas the small wine companies follow often an informal strategy that resides within "the head and the heart of the owners". Strangely, literature on wine business strategy rarely integrate innovation as a common key point of the business strategy of both large and small/medium sized wine companies.

While the disruptive impact of IT technologies on business strategy has been underlined in different other industries, the literature seems to show that the five major strategies adapted by the wine industry are identified in the matrix of Michael Porter [9] in which a market target horizontal axis defines a niche vs. broad market positioning and a competitive focus vertical axis is structured in two parts, the low-cost market segment vs. differentiated market segment. The strategies illustrated in Fig. 1 are: lowcost niche, differentiated niche, low-cost broad market, differentiated broad market and portfolio strategy that is pursued by the global players such as Foster, Constellation Brands, LVMH, Concho y Toro, Gallo, Diageo and others. In this context, the differentiation strategy based on the product and service innovations seems to do well while developing a unique attribute such as a special appellation

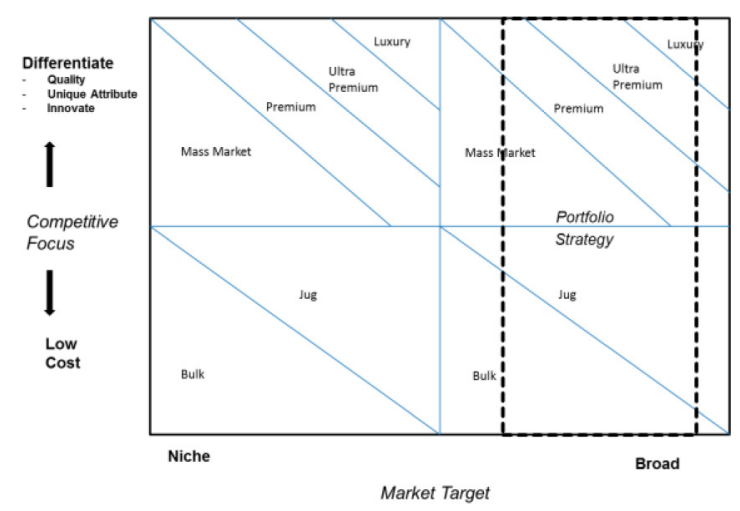

Source: L.Thach, 2008.

Figure 1. The existing WBS around the world.
- for example the Champagne brand name - has been identified as a key factor to compete well in the global wine market [8].

But there are other variables that must be considered to define the new competencies and skills needed in the wine company. The customer awareness, the appellation issues, the winery reputation and the confusion created by the presence of thousands labels on the global wine market should be included in the wine business strategy definition. Even more, the impact of IT technologies in the wine business, especially in the relationship between producers and final customers, can bring huge changes in the way wineries sell their products. The IT new devices and softwares like the new APP, smartphone and video tools seem to be limited to the wine enthusiasts and wine-bloggers who want to discover the vineyards around the world, tell stories gain, visibility on the web and eventually try to run a community manager role for some proactive wineries.

Yet, each year the Wine Industry Technology Symposium (WITS) that was created in 2005 in Napa, California, by a group of wine industry and technology professionals is developing different initiatives to foster learning and debate around technology solutions for the wine industry. New marketing and sales models strongly supported by the evolution of the IT technologies such as the Direct to Consumer (DTC) business are exploding in the US market, but most part of the wine business research literature remain focused on two main subjects: (1) the impact of the UE policies and appellation issues in term of cost, investment and innovation, and (2) the exploration of the customer perception and behavior after tasting/already knowing something about the wine/ brand/reputation.

Actually, the implementation of the IT technologies is heavily changing the generic wine business value chain - especially the distribution, marketing and sales and the service "routines" - creating a real gap between the traditionalist and the proactive wineries. The IT technologies are allowing the innovative companies called "proactives" to acquire a new vision of their final customer and to strengthen their relationship. In the same way that in other industries a new marketing area is emerging with the innovative concept of customer experience. The couple market/ low cost or differentiation should integrate the elements of the customer experience that are rarely approached together. The Customer experience approach compares the perception of the consumer before and after tasting considering the customer behavior in a sequential perspective (see Fig. 2).

The correlation between quality, perception and the "potential" customer behavior are the main findings. Longterm relationships between the producer and the final customer are generally missed and partially approached in the studies that explore the wine tourism and event marketing initiatives [10]. The opportunity to create an interaction between the winery and the final customer are recently explored in the US literature [11] while most of the research papers are focused on the "cash and carry" effects - essentially in terms of revenues - that bring the existing E-commerce website to the winery [12].

By the way, various experts highlight that industry changes require innovation in the wine business education proposals. During the first conference on wine business 


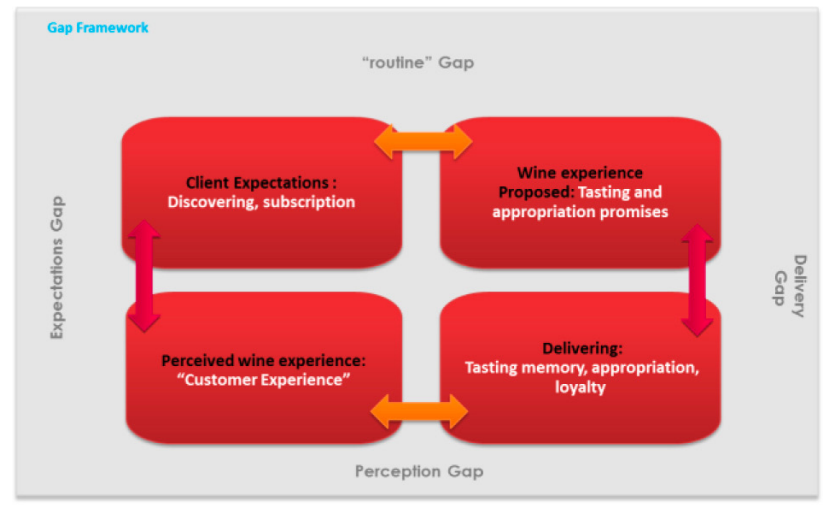

Source: WTBA.

Figure 2. The concept of customer experience.

education, Peter Mondavi noted that it was important to have "the wisdom of the market; getting the wine in the bottle is easy to do". Moreover, a series of new published indicators such as the brand awareness regarding the still wines and champagne - provides each year by the Drinks business magazine - show there has been a shift in focus from product to sales that increase the importance of the wine business professional in the wine business value chain. Innovation is needed at all its key points especially the marketing, sales and communication fields. The diffusion of new forms of direct marketing such as DTC business could be a signal of the digital revolution the wine industry is being to live thanks to the implementation of the IT technologies.

Innovation is said to be important to the long-term viability of a company as it can help to create a competitive advantage. Kim and Maubourgne [13] suggested that in order to survive and thrive in increasingly competitive markets, innovation is the only solution while there is also an evidence that the proactives sustain a higher level of performance and grow faster than non-innovators [14].

\subsection{Role of innovation}

Coming up with a practical definition of innovation is harder than it sounds, particularly if the goal is to rank every new initiative or product by its "innovativeness". It can take several months for a company to hammer out its definition of innovation. As a starting point, it is important to look back over a decade or two and identify the sorts of ideas that have produced noticeable margin and revenue gains.

Following an article published in April 2015 by Gary Hamel and in the Harvard Business review there are ways of measuring innovation performance and a comprehensive dashboard should track:

- Inputs: the investment dollars and employee time devoted to innovation, along with the number of ideas that are generated internally each month or sourced from customers, suppliers, and other outsiders.

- Throughputs: the number and quality of ideas that enter the pipeline after initial screening, the time it takes for those ideas to move from concept to prototype to reality, and the notional value of the innovation pipeline.

- Outputs: the number of innovations that reach the market in a given period, the percentage of revenue derived from new products and services, and the margin gains that are attributable to innovation.

- Leadership: the percentage of executive time that gets devoted to mentoring innovation projects, and 360-degree survey results that reveal the extent to which executives are exhibiting pro-innovation behaviors.

- Competence: the percentage of employees who have been trained as business innovators, the percentage of employees who have qualified as innovation "black belts," and changes in the quality of ideas that are being generated across the firm.

- Climate: the extent to which the firm's management processes facilitate or frustrate innovation, and the progress that is being made in removing innovation blockages.

- Efficiency: changes over time in the ratio of innovation outputs to inputs.

- Balance: the mix of different types of innovation (product, service, pricing, distribution, operations, etc.); different risk categories (incremental improvements versus speculative ventures); and different time horizons.

There is presently no published research investigating the different modes of innovation with regards to the wine industry [15]. As for an agricultural and industrial production process, innovation concerns the implementation of new technologies both in the production process and wine. But other initiatives for innovating regard the marketing and sales field. Some new initiatives are showing how some wineries/highly regarded wine brands are revolutionizing their marketing strategy using business technology to attract, engage and sell to customers every time, on every device and on the most functional way. For example, At the beginning of December 2014, Veuve Clicquot launched an unlimited edition of wines called "Clicquot Mail" along with a new digital marketing program in which there is a real effort to fill the gap between what the final customers want and what the winery can deliver thanks to a number of readily available initiatives implement on native apps, wearable platforms and the web.

These kind of initiatives naturally represent a reaction to changes in the external market environment to capture the imagination of consumers [16] to create a fresh and proactive image. Consumers are increasingly expecting a rich customer experience. At the same time, digitization is boosting consumer purchasing power with new free services while the quality of wine production is greatly improving. The disruption caused by digitization can create or destroy significant value for companies but it depends on their starting positions and on how well they respond to the shifting consumer behavior. But the Veuve Clicquot business experience for example shows that the opportunities seems to outweigh the risks. It seems that the large wine companies/divisions that deliberately and effectively implement comprehensive digital transformations will be able to capture most of the benefits linked to this historic economic pivot while avoiding the pitfalls. 
Today, IT technologies are a growing support of the core wine business which is essentially oriented to the selling product issues (see Fig. 3).

Three kind of new technologies are now entering in the wine industry:

- Data mining that represents a process used to extract information from a data set.

- Web technologies or internet technologies comprehensive of www technologies, social networks and web applications.

- Business supports systems that support the business activities (such as CRM, billing systems, business intelligence applications).

In that context, digital marketing is supported by the web technologies giving then to the wine companies a digital access to new markets and final customers. Each producer/ innovator can choose either to develop internal competencies or to externalize. For instance, various high-tech US small companies provide such services.

Most of the small/medium sized companies question the usefulness of changing their routine integrating new IT technologies and it seems that this resistance is typical of the traditional family owned wineries.

On the other hand, the new generation has become aware that storytelling could help to build the brand awareness of their wineries using the social networks. Whether by incorporating the winery or wine-maker's history in the branding, or hosting special events and activities to complement tastings, wineries and vineyards are finding innovative ways of telling their stories, and inspiring consumers to create their own stories based on their experiences with wine. But it is not a common sense for all. On the other side, it is not up to the customer to adapt to the mindset of the producer. It is the producer duty to listen to the consumer. Wineries have to observe their final customers, up close and over time, and then reflect on what they have learned. Any innovation tentative that does not start by helping individuals to see the world with "fresh eyes" will almost inevitably fall short of expectations.

As an evidence technical wine knowledge is an advantage to sell wine but it seems to be a fake pre-requisite regarding the emerging new competencies required to manage a wine company and to line up the marketing and communication strategy with the customer expectations using the IT technologies as a support. In that sense, a successful future seems to be open to the new "hybrid-profession"

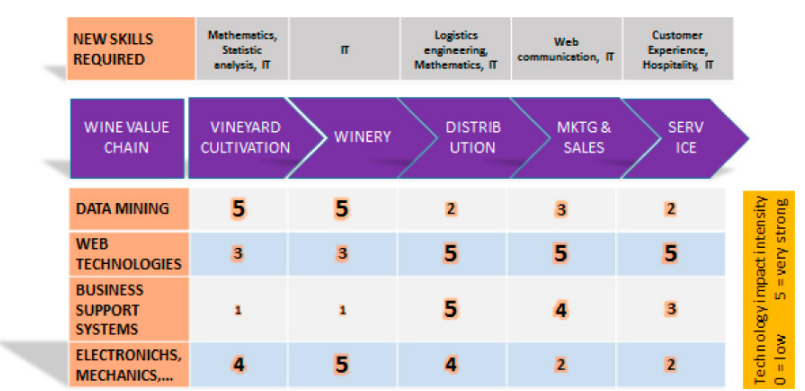

Source: WTBA.

Figure 3. IT implementations in the wine industry value chain. that requires competencies and skills in Economics (strategy management, marketing, supply chain, internationalization and statistics), information technology (data mining, web technology, business support systems) and human sciences (psychology, sociology, cognitive sciences and semantics for data mining). But there is no evidence that all the components of innovation have to be internalize in the wine company especially when it concerns the support/ application of the IT technologies to the business model of the winery.

In this new context, the producer/innovator has to evaluate the opportunity to internalize these competencies investing in a higher wine education degree and/or hiring new professionals - or to externalize these new tasks to a qualified provider. Looking at other sectors it appears that it is the gap between the innovation impact on the market and the sectorial ability to innovate that define the producer's decision.

Setting an horizontal axis with a two-part penetration level of innovation - low to high - into the market and a vertical axis with two modes of innovate (internally or externally) for the wine company (see Fig. 4) we can show four innovation strategies that should allow the producer to reach a new competitive advantage:

- Traditional business strategy with a low innovation adoption.

- Change of the business model buying innovation.

- Traditional business strategy introducing a high level of innovation internally.

- Radical transformation of the business model through innovation.

To put the customer at the core of the strategy, the producer/innovators needs to transform drastically the culture, organization and business model of the company. Digital technology becomes a key driver of the competitive advantage of the winery and the relative knowledge should be ideally transferred to the decision-maker. The producer must understand what technologies are needed to develop the winery business. In fact, a recent research by Bain \& Company reveals the positive effects of customer obsession: a $5 \%$ increase in customer retention can

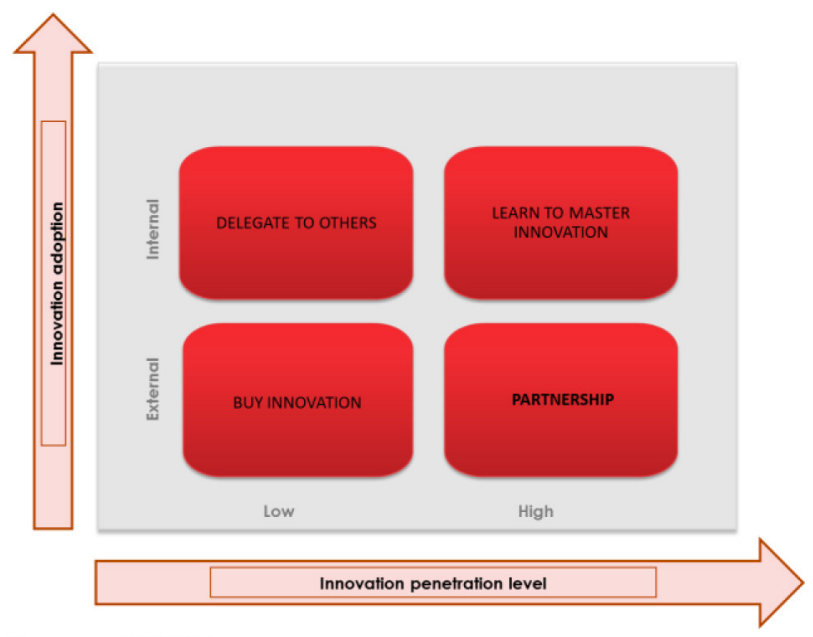

Source: $\overline{\mathrm{WTBA}}$.

Figure 4. Strategical choices for innovation adoption. 
increase profits by $25-95 \%$. That is why the most loved brands - evolving mostly in the luxury and retail industries - prioritize customer experience: according to Forrester's Customer Index, 39\% of outperforming companies have developed a fully integrated omni-channel strategy, connecting the physical and digital experience.

The innovation capacity of industry depends not only on large enterprises with market power but crucially on ambitious entrepreneurs and small enterprises aiming for radical innovations and fast growth. They are the small innovative companies that create the majority of new jobs for example in the European community [17]. On the other hand, it appears that MBA students are mostly hired in the large corporations while the small and medium-sized companies attract people with very different profiles of study [18]. Finally, looking at the new innovative initiatives run in the wine industry, it appears that the business strategies involving a radical transformation of the business model through innovation (Diageo, LVMH) are coming from other connected sectors such as spirits and luxury.

As shown in the Fig. 5, it appears then that it exists two kinds of innovation strategies - independently from the company size - in the wine industry: (1) the innovation strategies based on the selling of products, (2) the innovation strategies based on the selling of experience.

In that context, the creation of new employment is closely linked with the kind of competencies required by the wine company/division. Project-based and team-working competencies are usually the most required in an innovation process while leadership is reserved to company evolving in a traditional business model designed for product selling. Innovation strategies based on the selling of experience require competencies and skills that are usually developed outside of the wine industry where the loyalty and retention programs are becoming the core business of the company.

\section{Conclusion}

While the implementation of IT technologies and the relative digital transformations require step-by-step wine businesses/divisions to commit new intellectual and material resources, the learning process should begin to grow unless the wine companies are prepared to meet the digital customer experience required by the consumers. From our study it appears that some large companies are yet implementing comprehensive digital transformations while the SMEs are not already at the starting point. In that context, MBA programs should be adapted to be able to deliver adequate competencies and skills both to the proactives and the traditional companies whatever their dimension.

\begin{tabular}{l|l|l|l|}
\hline $\begin{array}{l}\text { Innovation } \\
\text { strategies }\end{array}$ & \multicolumn{1}{|c|}{ SMEs } & Large wine estates & $\begin{array}{c}\text { Global leading } \\
\text { companies }\end{array}$ \\
\hline $\begin{array}{l}\text { Innovation based } \\
\text { on the selling of } \\
\text { products }\end{array}$ & Old world wineries & $\begin{array}{c}\text { Groupe Castel; Grands } \\
\text { Chais de France }\end{array}$ & Pernod Ricard \\
\hline $\begin{array}{l}\text { Innovation based } \\
\text { on the selling of } \\
\text { experience }\end{array}$ & $\begin{array}{l}\text { Californian wineries } \\
\text { (Montelena); Chateau } \\
\text { Musar, Casella wines } \\
\text { (Yellow tail) }\end{array}$ & Foster estates (Beringer) & $\begin{array}{c}\text { Veuve Clicquot, Moet } \\
\text { Hennessy (LVMH); } \\
\text { Diageo }\end{array}$ \\
\hline
\end{tabular}

Source: WTBA.

Figure 5. Existing innovation strategies and company dimension.
Programs must include sessions of digital marketing providing both competencies on internet and on the cognitive science and semantics so as to help the company to strengthen the relationships with the final customers. Finally, it seems that innovation should ease the creation of new employments especially into the "proactive" wine companies where the decision-maker has the needs to learn how to transform their organization and to absorb the competencies (and best pratices) developed in other retail sectors such as luxury to reach new revenue gains.

What would be needed to accomplish a better adequacy between the MBA programs and the wine company needs? The main ingredient is closer collaboration between the universities/business schools and the overall wine industry whatever the dimension of the wine companies:

- The business schools and universities providing MBA programs in wine business can fix new collaboration with other universities that further research and educate tomorrow digital talents in the cognitive sciences and semantics for data mining, while discussing with private companies how best to anticipate future competence and skill needs.

- The large companies/divisions that can set an example with their own digital transformations and by investing in digital partnerships with small- to medium-sized wine companies; their financial know how could allow them to act as venture capitalists, backing the start-updriven digital ecosystem and stimulating the creation of new jobs/internships.

\section{References}

[1] T. Zalan, G. Lewis, A Strategic Approach to the Analysis of Global Wine Industry Positioning (AWBR, Geisenheim, 2014)

[2] Conference proceedings on the First conference on Wine Business Education (Sonoma State, 2012)

[3] A. Stasi, A. Muscio, G. Nardone, Drivers of ecoinnovation in italian wine industry (Università degli Studi di Foggia, 2013)

[4] V. De Marchi, Environmental innovation and $R \& D$ cooperation: Empirical evidence from Spanish manufacturing firms (Research Policy 41, 614-623, 2012)

[5] M. Porter, The French wine cluster: microeconomics of competitiveness (Harvard Business School, winter, 2013)

[6] G. Seth, All marketers are liars (Portfolio, New York, 1999)

[7] G. Seth, Permission marketing: turning strangers into friends, and friends into customers (Simon \& Schuster, New York, 2009)

[8] L. Thach, Wine business strategy (Chapter 2 in Wine, a global business, Miranda Press, 2008)

[9] M. E. Porter, The Competitive Advantage: Creating and Sustaining Superior Performance (Harvard Business School, 1985)

[10] Z. Szabo, The Role of Event Marketing in Case of the Buda Castle Wine Festival (AWBR, 2014)

[11] M. MacGarry Wolf, M. Wolf, U.S. Wineries Use Social Media to Engage Consumers, Improve Brand Image and Increase Revenue (AWBR, Gesheneim, June 2014) 
[12] L. M. Higgins, all, Click, Ship, Sip: Who is the Online Wine Buyer?, (AWBR, Geisenheim, 2014)

[13] W. C. Kim, R. Maubourgne, Blue Ocean Strategy (Harvard Business School Press, 2005)

[14] B. S. Tether, What is innovation? Approaches to distinguishing new products and processes from existing (Centre for Research on Innovation and Competition, Working Paper 2003)

[15] D. Doloreux, T. Chamberlin and S. Ben-Amor, Modes of innovation in the Canadian wine industry (IJWBR 25,1 2012)
[16] L. King, L. Forbes, Exploratory analysis of marketing innovations in the New Zealand wine industry (Faculty of Commerce Working Paper no. 6, September 2013)

[17] http://ec.europa.eu/research/participants/data/ref/h2020/wp/2014_2015/ main/h2020-wp1415-sme_en.pdf

[18] http://mbapodcaster. com/podcast/ wine-mba/ 